\title{
Factor Affecting Adoption of IPM Technology; an Example from Banke and Surkhet District of Nepal
}

\author{
Arjun Khanal ${ }^{1, \text { * }}$, Punya Prasad Regmi ${ }^{2}$, Gopal Bahadur KC ${ }^{3}$, Dilli Bahadur KC ${ }^{4}$, \\ Kishor Chandra Dahal ${ }^{5}$ \\ ${ }^{1}$ Institute of Agriculture and Animal Science, Tribhuwan University, Kirtipur, Kathmandu \\ ${ }^{2}$ Agriculture and Forestry University, Rampur, Chitwan \\ ${ }^{3}$ Department of Plant Pathology, Institute of Agriculture and Animal Science, Kirtipur, Kathmandu \\ ${ }^{4}$ International Maize and Wheat Improvement Center (CIMMYT), Lalitpur, Nepal \\ ${ }^{5}$ Department of Horticulture, Institute of Agriculture and Animal Science, Tribhuwan University, Kirtipur, Kathmandu \\ Email address: \\ arjunkanal15@gmail.com (A. Khanal), arjun.khanal@adbl.gov.np (A. Khanal) \\ ${ }^{*}$ Corresponding author
}

\section{To cite this article:}

Arjun Khanal, Punya Prasad Regmi, Gopal Bahadur KC, Dilli Bahadur KC, Kishor Chandra Dahal. Factor Affecting Adoption of IPM Technology; an Example from Banke and Surkhet District of Nepal. International Journal of Agricultural Economics.

Vol. 5, No. 6, 2020, pp. 304-312. doi: 10.11648/j.ijae.20200506.19

Received: October 29, 2020; Accepted: November 9, 2020; Published: MM DD, 2020

\begin{abstract}
This study evaluates the factor affecting adoption of IPM technology in Banke and Surkhet district of Nepal. An adoption analysis is necessary for describing and measuring the adoption of IPM technologies, which can provide important policy information that can lead to improvement of farmers' lives. The dependent variable in the following adoption analysis can take four values 1, 2, 3 and 4, indicating different levels of adoption. Due to the ordered nature of the dependent variable the model used was an ordered probit model. The determinants of adoption included in the present model belong in three main categories: socio-demographic, economic, and institutional characteristics. Five variables were statistically significant at $1 \%$ level for practicing IPM technology, they were; experience, training, MPC, mass media, and farmer field school. Two variables were statistically significant at 5\% level for practicing IPM technology, they were; awareness of pesticides alternatives and field day. One variable age is statistically significant at $10 \%$ level for practicing IPM technology. Seven others variables namely gender, total family member, education, farm area, extension agent, credit and visit were statistically non significant. The sign of the coefficient in the coefficient columns shows the type of impact, positive or negative, by the particular variable.
\end{abstract}

Keywords: IPM Technology, Factor Affecting, Adoption and Market Planning Committee

\section{Introduction}

Agriculture is the major sector of Nepalese economy. It provides employment opportunities to around 65 percent of the total population and contributes about 27 percent in the GDP. Vegetable production is associated with heavy use of chemical inputs - pesticides and fertilizers - to manage pests and optimize profits. Most pesticides are applied in liquid form using back pack sprayers and not all farmers utilize protective equipment while spraying [1]. Pests are a major constraint to increased vegetable production. Therefore support has grown in Nepal for development and diffusion of integrated pest management (IPM), also known as Integrated Pest Control
(IPC), as a broad based approach for economic control of pests. IPM aims to suppress pest populations below the economic injury level (EIL). IPM emphasizes the growth of a healthy crop with the least possible disruption to agro-eco systems and encourages natural pest control mechanisms. There are various ways to improve farmers' lives in Nepal using IPM CRSP techniques and approaches, such as developing resistant varieties, educating farmers though Farmer Field School (FFS) etc. One way to improve the lives of farmers in most developing countries is through adoption of innovative agricultural technologies. Considering the fact that the majority of the population in least developed country depends on agricultural production, new technologies may provide an 
opportunity to increase production and income significantly [2].

\section{Method}

\subsection{Factors Determining Adoption of IPM Technologies in Nepal}

An adoption analysis is necessary for describing and measuring the adoption of IPM technologies, which can provide important policy information that can lead to improvement of farmers' lives. The objective of this study is to determine the factors that affect adoption of IPM technologies in Nepal, using survey data from two districts.

\subsection{The Econometric Model: An Ordered Probit}

The dependent variable in the following adoption analysis can take four values 1, 2, 3 and 4, indicating different levels of adoption. Due to the ordered nature of the dependent variable the model used was an ordered probit model. The ordinary least squares (OLS) models are not the adequate estimators for these types of cases because they are not necessarily consistent in the probability discrete choice framework. The OLS estimator measures the change in the dependent variable given one unit change in the independent variable and could offer results that are negative or exceed the maximum value. The ordered probit model ensures a result that lies within the interval of interest [3]. The ordered probit model was also used by Mauceri [4], while Feder and Umali [5] also suggested the use of the logit/probit models for technology adoption analysis. The ordered probit requires a dependent variable that, as suggested by the name, is ordered, which means that the assigned values are no longer arbitrary but are rather ordered responses taking on values $\{0,1,2 \ldots . \mathrm{J}\}[6]$.

In their study, [7] pointed out that adoption can be defined by level, while [4] used the level defined adoption approach (ordered probit model) in the adoption analysis.

The dependent variable in this analysis was also defined by levels: none, low, medium and high which correspond respectively to $1,2,3$, and 4 .

1 indicated no adoption, meaning that none of the IPM practices were used by that particular farmer.

2 indicated low adoption, meaning that one of the IPM practices was adopted by the particular farmer.

3 indicated medium adoption, meaning that two IPM practices were adopted.

4 indicated high adoption, meaning that three of more practices were adopted by the particular farmer.

The dependent variable was created by looking at nine different variables, which referred to the usage of IPM practices, and using the above guidelines. The practices used to define the dependent variable were: soil amendment, mulching, bagging, soil solarization, pheromone traps, biofertilizers, bio-pesticides, jholmol and grafting. The saw dust, poultry refuse and mustard/neem oil cakes are soil amendments (bedding). The farmers were asked whether they used these practices. Looking at the nine variables, If the farmer didn't used any practices 1 was registered, if any one practices was used a 2 was registered, which indicated low IPM adoption, if any two practices were used a 3 was registered, which indicated medium level of IPM adoption and if any three or more practices were used a 4 was registered, which indicated maximum level of IPM adoption.

According to [6], a latent variable model can be used to derive the ordered probit model, where $\mathrm{y}^{*}$ is determined by

$$
\mathrm{y}^{*}=\mathrm{x} \beta+\mathrm{e}, \quad \mathrm{e} \mid \mathrm{x} \sim \operatorname{Normal}(0,1)
$$

where $\beta$ is $\mathrm{K} x 1$ and $\mathrm{x}$ does not contain a constant.

$$
\begin{array}{ll}
\mathrm{y}=0 & \text { if } \mathrm{y}^{*} \leq \alpha 1 \\
\mathrm{y}=1 & \text { if } \alpha 1<\mathrm{y}^{*} \leq \alpha 2 \\
\mathrm{y}=\mathrm{J} & \text { if } \mathrm{y}^{*}>\alpha \mathrm{J}
\end{array}
$$

where $\alpha 1<\alpha 2 \ldots<\alpha \mathrm{J}$ are the cut points or threshold parameters. The number of threshold parameters depends on the number of values taken by $y$, for instance if the values of $\mathrm{y}$ are 0,1 and 2 than there will be two cut points $\alpha 1$ and $\alpha 2$. In the case of the adoption analysis of IPM adoption in Nepal, y takes on the values 1, 2, 3 and 4, resulting in three cut points $\alpha 1, \alpha 2$ and $\alpha 3$.

Given the standard normal assumption for $\mathrm{e}$, the conditional distribution of $\mathrm{y}$ given $\mathrm{x}$ can be derived by calculating each response probability:

$$
\begin{gathered}
\mathrm{P}(\mathrm{y}=0 \mid \mathrm{x})=\mathrm{P}\left(\mathrm{y}^{*} \leq \alpha 1 \mid \mathrm{x}\right)=\mathrm{P}(\mathrm{x} \beta+\mathrm{e} \leq \alpha 1 \mid \mathrm{x})=\Phi(\alpha 1-\mathrm{x} \beta) \\
\mathrm{P}(\mathrm{y}=1 \mid \mathrm{x})=\mathrm{P}\left(\alpha 1<\mathrm{y}^{*} \leq \alpha 2 \mid \mathrm{x}\right)=\Phi(\alpha 2-\mathrm{x} \beta)-\Phi(\alpha 1-\mathrm{x} \beta) \\
\cdots \\
\cdots \\
\mathrm{P}(\mathrm{y}=\mathrm{J}-1 \mid \mathrm{x})=\mathrm{P}\left(\alpha \mathrm{J}-1<\mathrm{y}^{*} \leq \alpha \mathrm{J} \mid \mathrm{x}=\Phi(\alpha \mathrm{J}-\mathrm{x} \beta)-\Phi(\alpha \mathrm{J}-1-\mathrm{x} \beta)\right. \\
\mathrm{P}(\mathrm{y}=\mathrm{J} \mid \mathrm{x})=\mathrm{P}\left(\mathrm{y}^{*}>\alpha \mathrm{J} \mid \mathrm{x}\right)=1-\Phi(\alpha \mathrm{J}-\mathrm{x} \beta)
\end{gathered}
$$

These probabilities sum to unity. If $\mathrm{J}=1$ that results in a binary probit model. The $\alpha$ and $\beta$ parameters can be estimated using maximum likelihood estimation (MLE) [6].

The MLE estimation is based on the distribution of $y$ given $\mathrm{x}$, the $\operatorname{Var}(\beta)$ is directly adjusted for the presence of herersokedasticity [3]. According to [6] the presence of heteroskedasticity in $\operatorname{Var}(e \mid \mathrm{x})$ changes the functional form entirely $\mathrm{P}(\mathrm{y}=1 \mid \mathrm{x})=\mathrm{E}(\mathrm{y} \mid \mathrm{x})$ indicating that probit would be inconsistent when $\beta$ is heteroskedastical though it makes little sense to care about the consistent estimation of $\beta$ when $\mathrm{P}(\mathrm{y}=1 \mid \mathrm{x}) \neq \Phi(\alpha, \beta)$. Another problem that [6] pointed out in the latent variable models was the normality assumption. If the assumption does not hold, it means that $\mathrm{G}(\mathrm{z}) \neq \Phi(\mathrm{z})$ and therefore $\mathrm{P}(\mathrm{y}=1 \mid \mathrm{x}) \neq \Phi(\alpha, \beta)$ which is a functional form problem. In order to obtain more flexible functional forms for $\mathrm{P}(\mathrm{y}=1 \mid \mathrm{x})$, the assumptions on $e$ could be relaxed.

MLE is the particular value of parameters that creates the greatest probability of observing the sample [3]. Considering the ordered probit functional form for the probability of 
success, taking the log of the both sides yields the loglikelihood function [6]:

$$
\begin{gathered}
\ell \mathrm{i}(\alpha, \beta)=1[\mathrm{yi}=0] \log [\Phi(\alpha 1-\mathrm{x} \beta)+1[\mathrm{yi}=1] \log [\Phi(\alpha 2-\mathrm{x} \beta)-\Phi(\alpha 1- \\
\mathrm{x} \beta)]+\ldots . .+1[\mathrm{yi}=\mathrm{J}] \log [1-\Phi(\alpha \mathrm{J}-\mathrm{x} \beta)]
\end{gathered}
$$

This log-likelihood function measures the probability of observing the sample data we have. By maximizing the loglikelihood function, the probability of observing the sample data is being maximized. The log-likelihood function is always negative.

The signs of $y^{*}$ in the model indicate positive or negative impacts on the probability of IPM adoption in the case of Nepal. According to equation above the probabilities in the case of Nepal can be written as follows:

$$
\begin{gathered}
\mathrm{P}(\mathrm{y}=1 \mid \mathrm{x})=\mathrm{P}\left(\mathrm{y}^{*} \leq \alpha 1 \mid \mathrm{x}\right)=\mathrm{P}(\mathrm{x} \beta+\mathrm{e} \leq \alpha 1 \mid \mathrm{x}) \\
\mathrm{P}(\mathrm{y}=2 \mid \mathrm{x})=\mathrm{P}\left(\alpha 1<\mathrm{y}^{*} \leq \alpha 2 \mid \mathrm{x}\right)=\mathrm{P}(\alpha 1<\mathrm{x} \beta+e \leq \alpha 2 \mid \mathrm{x}) \\
\mathrm{P}(\mathrm{y}=3 \mid \mathrm{x})=\mathrm{P}\left(\alpha 2<\mathrm{y}^{*} \leq \alpha 3 \mid \mathrm{x}\right)=\mathrm{P}(\alpha 2<\mathrm{x} \beta+e \leq \alpha 3 \mid \mathrm{x}) \\
\mathrm{P}(\mathrm{y}=4 \mid \mathrm{x})=\mathrm{P}\left(\mathrm{y}^{*} \geq \alpha 4 \mid \mathrm{x}\right)=\mathrm{P}(\mathrm{x} \beta+e \geq \alpha 4 \mid \mathrm{x})
\end{gathered}
$$

where the $y$ values $1,2,3$ and 4 are the corresponding values of the dependent variable indicating none, low, medium and high adoption, respectively.

\subsection{Determinants Affecting Adoption}

Different models have been applied to look at determinants of adoption. [8] point out that adoption process is complex and requires accounting for numerous social, economic, cultural, and institutional determinants. The determinants of adoption included in the present model belong in three main categories: socio-demographic, economic, and institutional characteristics. The same categories were used by [4] and [9].

$i$. Category I. Socio-demographic Characteristics

Age-Farmer's age

Age is expected to negatively affect adoption. Older and more experienced farmers may be less likely to experiment with new technologies while younger farmers are less risk averse and more likely to adopt new techniques.

Gender-Farmer's Gender (Female=1, Male=0)

Gender is a binary variable distinguishing between male and female farmers. Gender analysis has been an important part of IPM IL research. "Yet there are many obstacles to incorporating women in IPM programs around the world, ranging from traditional culture to the fact that gender influences access to resources such as land, labor, education and credit-all important to the adoption of IPM [10]. [4] and [9], both found that the farmer's gender (male or female) was not a significant variable affecting technology adoption, in addition [9] also suggests that the effects of the variable are indeterminate. [8] also found the effects of this variable to be indeterminate.

Total family member-Number of family member in the household

Total family member is a continuous variable that represent the total number of family member in the household. It is expected that more number of economically active members in the household were more open to adopt
IPM technologies. This variable measured the labor availability which is a factor in adoption [4]. A study by [11] found the variable to be significant and positively affecting the adoption of IPM technologies. Another study however, found that family size was negatively correlated with adoption in the case of alley farming by farmers in the forest zone of southwest Cameroon [12].

Education-Level of farmer's education

Education is a continuous variable that represent the number of years of education. More educated farmers were expected to be more open to adoption of innovative technologies, such IPM technologies. [13] categorized education along with experience, as a part of human capital, and point out that a higher endowments of human capital affects productivity positively.[14], found that higher levels of education were associated with higher adoption. Another study found that education was not a significant variable affecting adoption of technologies [5]. A study by [8] hypothesized a positive sign for the education variable based on the fact that higher human capital should increase adoption.

Experience-Farming experience

Experience, is a binary variable that represents the farming experience. According to [13], farm experience along with education could be represented as human capital which positively impacts adoption. Experience is expected to be positively affecting adoption, because more experienced farmers may know the benefits of IPM and can practice IPM technology.

ii. Category II. Economic Characteristics

Farm area-Total size of farm area (including own, rented, leased etc. land)

Farm area, is a continuous variable measuring the total land holdings in hectare. [4] used per capita measure of the land size and found that the variable had no significant impact on adoption while the signs in the different model adaptations were conflicting. [4] pointed out that the difference in the signs may be due to the nature of the IPM technology; larger farms are expected to adopt more capital intensive technologies while smaller farms are expected to adopt more labor intensive technologies. In another study farm size was found to be negatively correlated with adoption [11].

iii. Category III. Institutional Characteristics

Training - Access to IPM training

Training is a binary variable that provides information about access to IPM training. This variable was expected to be positively impact on the adoption of IPM technologies.

Extension agent - distance $(\mathrm{km})$ to the nearest extension agent

Extension agent is a continuous variable measuring the distance in kilometers to the nearest extension agent. The correlation with adoption is expected to be negative. [15] found positive correlation between adoption and farmers' having contacts with extension. According to [9] extension contacts are positively related to adoption.

Credit-Access to credit

Credit is a binary variable that provides information about access to credit from financial institution. This variable was expected to be positively impact on the adoption of IPM technologies. 


\section{Awareness - Awareness of pesticide alternatives}

Awareness is a dummy variable that indicates whether the farmer is aware of the pesticide alternatives. It is expected that farmers who are aware of the pesticide alternatives will be higher adopters than the ones that are not aware.

$M P C-$ Member of $M P C$

MPC is a dummy variable that indicates whether the farmers were member of MPC. It is expected that farmers who are member of MPC will be higher adopters of IPM than the ones that are not member of MPC.

Mass media-Received information

Mass media is a dummy variable indicating whether farmers received information of IPM technology. It is expected that farmers who received information through mass media will be higher adopters.

FFS-Attended a farmer field school organized by DADO, IPMIL or any other

Farmer Field School (FFS) is a dummy variable indicating whether farmers attended FFS organized by different agencies. It is expected that farmers who attended FFS will be higher adopters.

Visit-Attended a visit organized by CBFs/agriculture officer

Visit is a dummy variable indicating whether farmers attended a visit organized by Community Business Facilitators (CBFs) or Agriculture Officer. It is expected that farmers who attended visit will be higher adopters.

Field day-Attended a field day demonstration organized by $C B F$ s/agriculture officer

Field day is a dummy variable indicating whether farmers attended a field day demonstration organized by Community Business Facilitators (CBFs) or Agriculture Officer. It is expected that farmers who attended field day demonstration will be higher adopters.

\section{Result}

\subsection{Description of the Study Area}

Banke District apart of province number five is one of the
77 districts of Nepal. The district, located in Mid-western Nepal with Nepalgunj as its district head quarters, covers an area of 2,337 $\mathrm{km}^{2}$ and had a population of 491,313 in 2011. Banke is bordered on the west by Bardiya district. Rapti zone's Salyan and Dang districts border to the north and east. To the south lies Uttarpradesh, India, a country in Asia; specifically Shravasti and Bahraich district of Awadh. East of Nepalganj the international border follows the southern edge of the Dudhwa Range of the Siwaliks.

Surkhet District apart of Karnali province is one of the ten districts of Karnali located about 600 kilometers (373 mi) west of the national capital Kathmandu. The district's area is $2,488.64$ square kilometers ( $960.87 \mathrm{sq} \mathrm{mi}$ ) which is longest in Nepal. It had population 350,804 in 2011 which male comprised 169,461 and female 181,381. It is the district head quarters of surkhet and commercial hub of the Karnali state of the new federal republic. Surkhet Valley is one the Inner Terai Valleys of Nepal. Bordering districts are Jajarkot, Dailekh, and Achham to the north, Bardiya banke district and Kailali to the south, Salyan district to the east, and Doti to the west.

\subsection{Household and Farm Characteristics}

Household and farm characteristics include total population, family size, occupation, etc. These characteristics were discussed briefly here under.

\subsubsection{Population and Household Characteristics in the Study Area}

Total population of the 500 sampled households were 2693 , In terms of gender, $50.25 \%$ male and $49.75 \%$ female in Banke district, Likewise $52.12 \%$ were male and $47.88 \%$ female in Surkhet district. Among the total population, $51.13 \%$ were male and $48.87 \%$ female in the study area. The study revealed that, most of the respondent were male $(51.2 \%)$ across the study sites (Table 1$)$. On comparison $52 \%$ in Banke district and 50.4\% in Surkhet district were male.

Table 1. Distribution of population by gender and sex of the respondents in the study area

\begin{tabular}{|c|c|c|c|c|}
\hline \multirow{5}{*}{ Gender of Population } & & \multicolumn{2}{|c|}{ Name of the Districts } & \multirow{2}{*}{ Total } \\
\hline & & Banke & Surkhet & \\
\hline & Male & $714(50.25)^{*}$ & $663(52.12)$ & $1377(51.13)$ \\
\hline & Female & $707(49.75)$ & $609(47.88)$ & $1316(48.87)$ \\
\hline & Total & $1421(100)$ & $1272(100)$ & $2693(100.00)$ \\
\hline \multirow{3}{*}{ Sex of the respondents } & Male & $130(52.00)$ & $126(50.4)$ & $256(51.2)$ \\
\hline & Female & $120(48.00)$ & $124(49.6)$ & $244(48.8)$ \\
\hline & Total & $250(100)$ & $250(100)$ & $500(100)$ \\
\hline
\end{tabular}

*figures in parentheses indicate percentage

(Source: Field Survey, 2017).

\subsubsection{Family Size of the Respondents}

The population distribution showed that the population size was greater in Banke district than Surkhet district, because of low level of literacy in the Banke district. The average family size of the surveyed sample was 6.45; particularly 7.84 and 5.05 in Banke and Surkhet district respectively. The average family size in the study area is greater than both Banke and Surkhet districts average of 5.18 and 4.81 respectively in Banke and Surkhet districts (CBS, 2011). The higher family size may be due to the lower illiteracy rate in the study area. The detailed of family size is described in Table 2. 
Table 2. Family size of the respondents in the study area

\begin{tabular}{|c|c|c|c|c|c|}
\hline \multicolumn{2}{|l|}{ Average family size } & \multirow{2}{*}{ Total Average(Mean \pm SD) } & \multirow{2}{*}{ Minim-um } & \multirow{2}{*}{ Maxi-mum } & \multirow{2}{*}{ Modal size } \\
\hline Banke $($ Mean \pm SD) & Surkhet $($ Mean \pm SD) & & & & \\
\hline $7.84 \pm 2.07$ & $5.05 \pm 1.78$ & $6.45 \pm 1.92$ & 1 & 12 & 5 \\
\hline
\end{tabular}

$\mathrm{SD}=$ Standard Deviation

\subsubsection{Distribution of the Economically Active Population in the Study Area}

Age of the family members were categorized in to three classes, less than 15 years, economically active age (1559 year) and more than 59 year. Majority of the population $(68.40 \%)$ was of economically active age. The percentage of economically active population was higher $(69.42 \%)$ in Surkhet district than Banke district (67.49\%). Similarly, the percentage of economically active population was higher (57\%) in Banke district than Surkhet district (53\%) [16]. The distribution of the economically active population in the study area was presented in Table 3.

Table3. Economically active population in the study area

\begin{tabular}{llll}
\hline & District & & Total \\
\hline Age group (Years) & Banke & Surkhet & $646(23.99)$ \\
\hline 15 & $348(24.49)^{*}$ & $298(23.43)$ & $1842(68.40)$ \\
$15-59$ & $959(67.49)$ & $883(69.42)$ & $205(7.61)$ \\
$>59$ & $114(8.02)$ & $91(7.15)$ & $2693(100)$ \\
\hline
\end{tabular}

*Figure in parenthesis indicates the percentage.

Source: Field Survey, 2017.

\subsubsection{Occupation}

In the study area it has been found that $65 \%$ of the sampled populations engaged in agriculture followed by foreign employment (13\%), service (11\%), business (6\%), wages (3\%) and others $(2 \%)$.

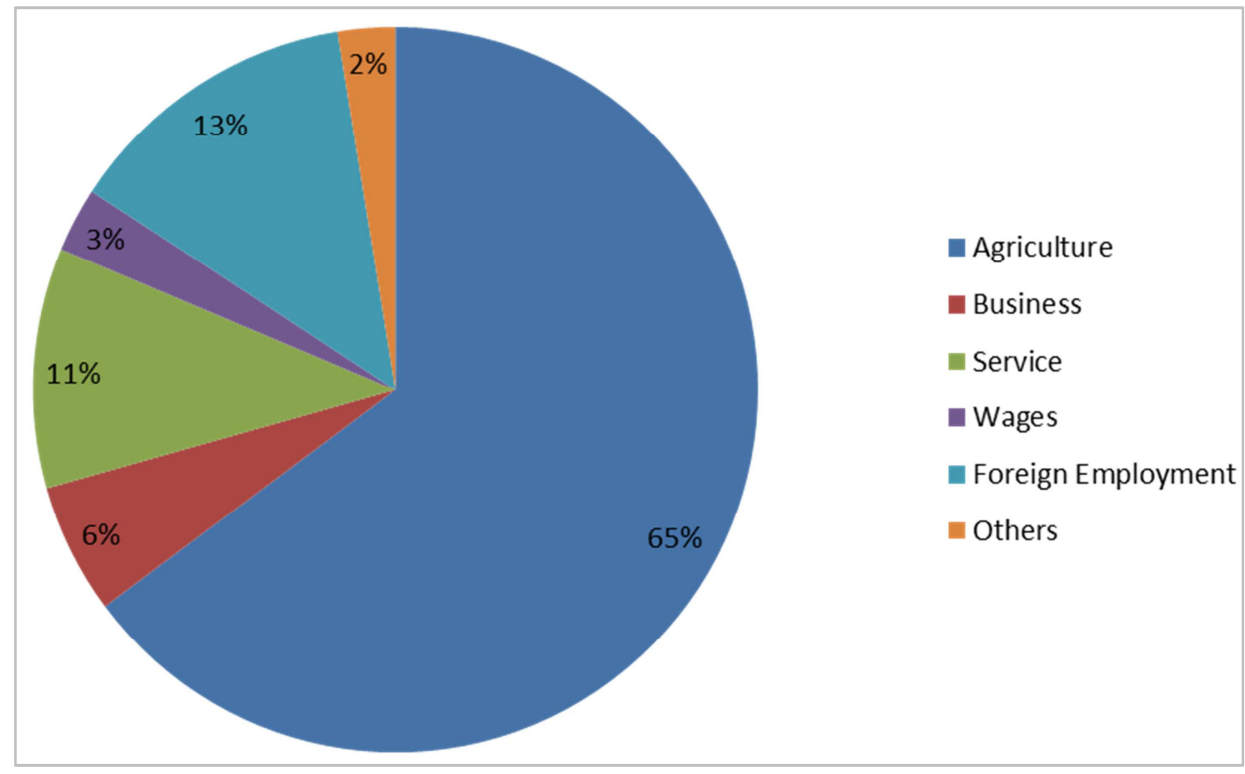

Source: Field Survey, 2017.

Figure 1. Occupation in the study area.

\subsection{Cultivation of Vegetables}

In the study area it has been found that $30 \%$ of the household has cultivated tomato followed by cauliflower/cabbage (27\%), bittergourd (17\%), cucumber $(16 \%)$ and eggplant $(10 \%)$ respectively. The study revealed that tomato is the major vegetable crops in the study area. 


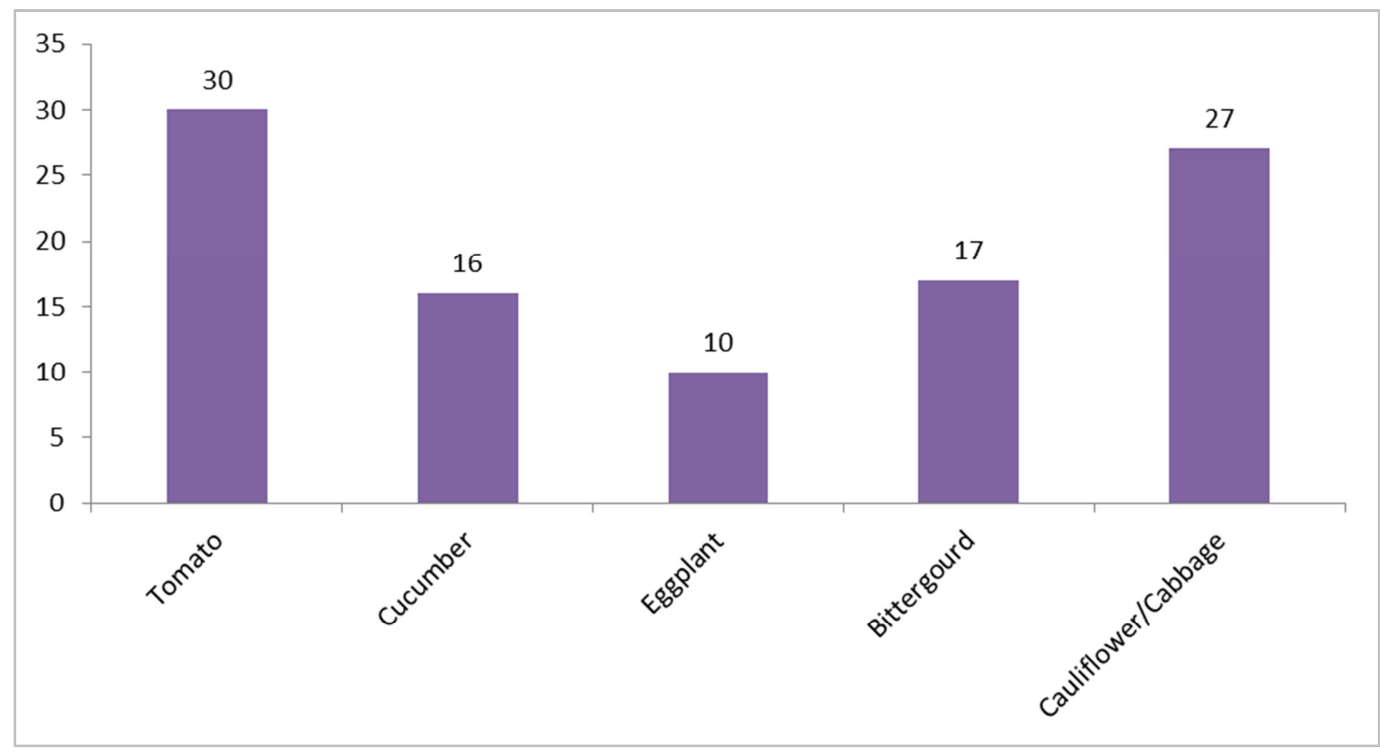

Source:FieldSurvey,2017.

Figure 2. Cultivation of vegetables.

\subsection{IPM Practices Used in the Study Area}

Just over $48 \%$ of the respondents indicated that they incorporated at least one IPM practice in their production of vegetables. Bio-fertilizers, Jholmol and bio pesticides were the most popular IPM practices, followed by the adoption of pheromone traps, soil amendments, mulching, soil solarization, bagging and grafting. Grafting technology was adopted the least, possibly due to the higher level of training and inputs required for successful adoption. Figure 3 depicts the percentage of total respondents adopting each of the nine different IPM practices.

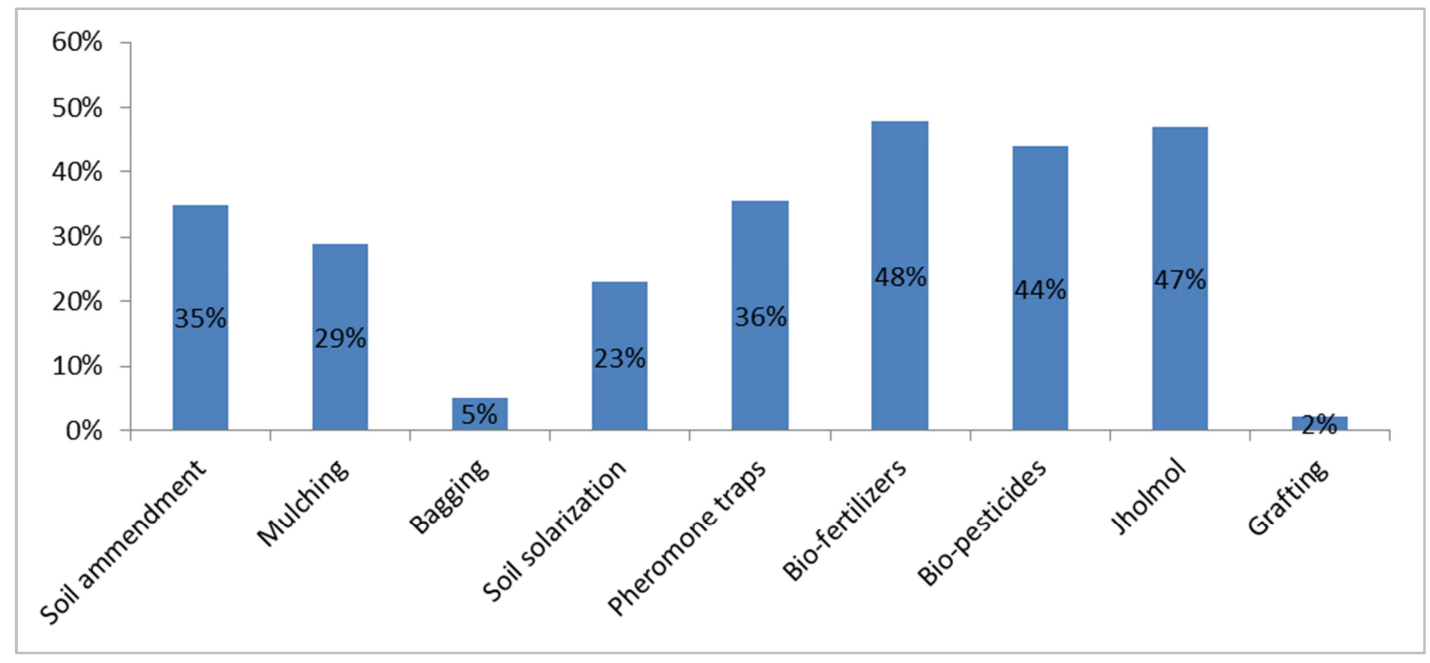

Figure 3. IPM practices used in the study area.

\subsection{Model of Adoption-an Ordered Probit Model}

In the study area the respondents' age ranged from 15 to 81 years, with an average age of approximately 44 years. Sixty five percent of the farmers reported having experienced (or a family member having experienced) a health problem due to pesticide use. Also according to the survey data, 49 percent of the respondents were female. Land holdings ranged between 0.20 and 4.7 hectare, with an average of 0.51 hectare. About $65 \%$ of the farmers responded that they had received IPM training. The number of family members ranged from 0 to 14 members, with an average of about 5 family members. In this study, approximately $27 \%$ of the surveyed farmers reported having education greater or equal to primary level or secondary level school. According to the reported usage of IPM practices, about 31 percent of the respondents were high adopters, while 25 percent were medium adopters. The following table provides a statistical summary of all variables used in ordered probit model. 
Table 4. Statistical description of the different variables used in ordered probi tmodel.

\begin{tabular}{|c|c|c|c|c|c|}
\hline Variable & Observation & Mean & Std. Dev. & Min & Max \\
\hline \multicolumn{6}{|c|}{ Category I. Socio-demographic Characteristics } \\
\hline Age & 500 & 43.564 & 12.54211 & 15 & 81 \\
\hline Gender $^{\#}$ & 500 & 0.604 & 0.4895542 & 0 & 1 \\
\hline Total Family Member & 500 & 5.368 & 1.952486 & 0 & 14 \\
\hline Education & 500 & 1.244 & 1.222888 & 0 & 6 \\
\hline Experience $^{\#}$ & 500 & 0.502 & 0.5004967 & 0 & 1 \\
\hline \multicolumn{6}{|c|}{ Category II. Economic Characteristics } \\
\hline \multicolumn{5}{|c|}{ Category III. Institutional Characteristics } & 4.732 \\
\hline Training ${ }^{\#}$ & 500 & 0.652 & 0.4768131 & 0 & 1 \\
\hline Extension Agent & 500 & 4.14 & 2.822824 & 0 & 17 \\
\hline Credit $^{\#}$ & 500 & 0.576 & 0.4946852 & 0 & 1 \\
\hline Awareness $\#$ & 500 & 0.25 & 0.4334464 & 0 & 1 \\
\hline MPC $^{\#}$ & 500 & 0.46 & 0.4988966 & 0 & 1 \\
\hline Mass Media ${ }^{\#}$ & 500 & 0.42 & 0.4940528 & 0 & 1 \\
\hline $\mathrm{FFS}^{\#}$ & 500 & 0.554 & 0.4975733 & 0 & 1 \\
\hline Visit $^{\#}$ & 500 & 0.58 & 0.4940528 & 0 & 1 \\
\hline Field day ${ }^{\#}$ & 500 & 0.516 & 0.5002444 & 0 & 1 \\
\hline \multicolumn{6}{|l|}{ Dependent variable } \\
\hline Adoption level & 500 & 2.074 & 0.9520172 & 1 & 4 \\
\hline
\end{tabular}

" represents Dummy variable.

The ordered probit model was used to examine the impacts of independent variables on ordered categories of adoption.

Table 5. Summary of the Ordered Probit Models' results.

\begin{tabular}{|c|c|c|c|c|c|c|}
\hline Variables & Coefficients & $\mathbf{P}>\mathbf{Z}$ & Standard error & $\mathrm{Dy} / \mathrm{dx} \mathrm{x}^{\mathrm{b}}$ & S.E. ${ }^{b}$ & $95 \%$ confidence \\
\hline Age & $0.0079266^{*}$ & 0.069 & 0.0043635 & -0.0025958 & 0.00143 & -0.0006256 \\
\hline Gender $^{\#}$ & -0.1736109 & 0.189 & 0.1321521 & 0.56163 & 0.04225 & -0.4326242 \\
\hline Total Family Member & -0.0202 & 0.478 & 0.02846 & 0.0066152 & 0.00932 & -0.0759805 \\
\hline Education & 0.0582199 & 0.178 & 0.0432331 & 0.19066 & 0.1416 & -0.0142955 \\
\hline Experience $^{\#}$ & $1.30664 * * *$ & 0.000 & 0.184757 & 0.4105749 & 0.5461 & 0.9445228 \\
\hline Farm Area & 0.950993 & 0.324 & 0.96461 & -0.0311434 & 0.3161 & -0.939607 \\
\hline Training ${ }^{\#}$ & $0.8782463 * * *$ & 0.000 & 0.1257185 & 0.2585803 & 0.341 & -1.12465 \\
\hline Extension Agent & -0.0229782 & 0.250 & 0.0199645 & 0.007525 & 0.00655 & -0.062108 \\
\hline Credit $^{\#}$ & 0.0466707 & 0.662 & 0.1066355 & -0.015317 & 0.03507 & -0.162331 \\
\hline Awareness ${ }^{\#}$ & $0.292734 * *$ & 0.014 & 0.1192825 & 0.0911467 & 0.03534 & 0.589446 \\
\hline $\mathrm{MPC}^{\#}$ & $0.7482044 * * *$ & 0.000 & 0.11909 & 0.2371979 & 0.3712 & 0.5147922 \\
\hline Mass Media ${ }^{\#}$ & $0.3839152 * * *$ & 0.003 & 0.129689 & 0.1228371 & 0.4063 & 0.1297295 \\
\hline $\mathrm{FFS}^{\#}$ & $0.5044135^{* * *}$ & 0.001 & 0.1528616 & 0.1613455 & 0.4816 & -0.8040167 \\
\hline Visit $^{\#}$ & 0.1193973 & 0.429 & 0.1510333 & 0.0393197 & 0.04990 & -0.1766226 \\
\hline Field day ${ }^{\#}$ & $0.3078111 * *$ & 0.028 & 0.1399108 & 0.1008703 & 0.0459 & 0.0335909 \\
\hline \multicolumn{7}{|c|}{ Summary Statistics } \\
\hline \multicolumn{3}{|c|}{ Number of observation $(\mathrm{N})$} & \multicolumn{4}{|l|}{500} \\
\hline \multicolumn{3}{|c|}{ Log likelihood } & \multicolumn{4}{|l|}{-497.82576} \\
\hline \multicolumn{3}{|l|}{$\operatorname{LR} \operatorname{chi}^{2}(15)$} & \multicolumn{4}{|l|}{287.35} \\
\hline \multicolumn{3}{|l|}{ Pseudo $\mathrm{R}^{2}$} & \multicolumn{4}{|l|}{0.2240} \\
\hline \multicolumn{3}{|l|}{ Prob $>$ chi 2} & \multicolumn{4}{|l|}{0.0000} \\
\hline
\end{tabular}

(\#) represents Dummy variable

***Significant at $1 \%$ level; $* *$ significant at $5 \%$ level; *significant at $10 \%$ level

${ }^{\mathrm{b}}$ Marginal change in probability (marginal effects after probit) evaluated at the sample means.

Ordered probit regression analysis focused on the 500 farmers engaged in agricultural activities and their adaptation strategies to combat for the practice of IPM technology. The wald test (LR chi 2) for the model indicates that, the model has good explanatory power at the $1 \%$ level. The Pseudo R2 was 0.2240 . The overall predictive power of the model $(74.67 \%)$ was quite high. The link test shows that _ hatsq was not significant meaning the model did not have omitted variables. For the interpretation of the model, marginal effects were driven from the regression coefficients, calculated from partial derivatives as a marginal probability. The interpretation was shown in Table 5 .

Ordered probit regression analysis shows that, five variables were statistically significant at $1 \%$ level for practicing IPM technology, they were; experience, training, MPC, mass media, and farmer field school. Two variables were statistically significant at 5\% level for practicing IPM technology, they were; awareness of pesticides alternatives 
and field day. One variable age is statistically significant at $10 \%$ level for practicing IPM technology. Seven others variables namely gender, total family member, education, farm area, extension agent, credit and visit were statistically non significant. The sign of the coefficient in the coefficient columns shows the type of impact, positive or negative, by the particular variable. According to [17] the impact on intermediate outcomes can't be inferred, which means that is it impossible to say whether the probability of no adoption is higher or lower than low level of adoption, or if the probability of medium adoption is lower or higher than the probability of high level of IPM adoption.

Age of household head is significant at $10 \%$ level for practicing IPM technologies. According to the findings, keeping other factor constant, a unit increase in number of age in the household head would result in 0.25 percent decrease in the probability of practicing IPM technologies. Age is typically found to be negatively correlated with adoption [12]. This relationship is explained by the assumption that as farmers grow older, there is an increase in risk aversion and a decreased interest in long-term investment in the farm. Younger farmers are typically less risk-averse and are more willing to try new technologies. [4] included age in the ordered probit model, pointing out that younger farmers are still in the process of learning the best management techniques. [15] found age to be negatively related to adoption of ally cropping. [14] found age to be negatively correlated and very influential factor in the adoption of IPM for coffee berry borer on Colombian farms.

Experience (dummy) is important variable affecting to adapt IPM technology. Experience of household head was positively significant at $1 \%$ level and unit increase in the year of farming experience would increases the probability of practicing IPM technology by $41 \%$. This might be due to the facts that, experienced farmers have high skills in farming activities, farm management, and they can minimize the impacts by adopting new innovation and adjusting their farming practices. Similar finding were reported by [18] and [19] in southern Africa. [20] also found that farm experience along with education could be represented as human capital which positively impacts adoption.

Higher the number of respondents accessing to IPM training (dummy), higher will be the probability of practicing IPM technology. The study shows that, number of respondents accessing to IPM training was positively significant at $1 \%$ level and keeping other factor constant, a unit increase in the number of respondents accessing training in IPM technology would result in $25.85 \%$ increase in the probability of practicing IPM technology. Numerous studies have found that the access to information has a positive impact on adoption $[4,9,11]$.

Awareness of pesticide alternatives (dummy) is important variable affecting to adapt IPM technology. Awareness of pesticide alternatives was positively significant at $5 \%$ level and unit increase in the awareness of pesticide alternatives would increase the probability of practicing IPM technology by $9 \%$. This might be due to the facts that, farmer who are aware of alternative pesticides may know the demerits of chemical fertilizers and their effect on health had maximum chance of practicing IPM technologies. Having sufficient knowledge about the technology enables farmers to optimize these decision-making processes [20]. The acquisition of knowledge may lead to a change in farmer perceptions about risk and profitability. Thus, farmers who are knowledgeable about profit-enhancing technologies will choose to adopt [21].

MPC (dummy) is important variable affecting to adapt IPM technology. Member of MPC was positively significant at $1 \%$ level and unit increase in the member of MPC would increases the probability of practicing IPM technology by $23.72 \%$. This might be due to the facts that, as MPCs allow farmers to aggregate smallholders' produce to meet market demand. Several farmer organizations join together and elect representatives to serve on the board of the MPC and have regular monthly meeting so that they can discuss on IPM technology and marketing strategy of the products.

Mass media (dummy) is also another important variable affecting for the adoption of IPM technology. Receiving information about IPM technology through mass media was positively significant at $1 \%$ level and unit increase in the receiving information about IPM technology through mass media would increase the probability of practicing IPM technology by $12.28 \%$. Mass media can cover larger area in short period of time.

Attending farmer field School (dummy) organized by DADO, IPM IL program was positively significant at $1 \%$ level and unit increase in attending farmer field school (FFS) might increase the probability of practicing IPM technology by $16.13 \%$.

Attending field day (dummy) organized by agriculture officer, community business facilitator was positively significant at 5\% level and unit increase in attending farmer field day might increase the probability of practicing IPM technology by $10 \%$.

\section{Conclusion}

This study revealed that $48.8 \%$ of the respondents were female with an average family size 6.45 . 68.40 percent of the population in the study area was economically active (15 to 59 years of age). The major source of income was agriculture $(65 \%)$, foreign employment $(13 \%)$, service $(11 \%)$, business $(6 \%)$, wages $(3 \%)$ and others $(2 \%)$. The study showed that tomato $(30 \%)$ is the major vegetable crops in the study area. Just over $48 \%$ of the respondents indicated that they incorporated at least one IPM practice in their production of vegetables. Bio-fertilizers, Jholmol and bio pesticides were the most popular IPM practices, followed by the adoption of pheromone traps, soil amendments, mulching, soil solarization, bagging and grafting. Grafting technology was adopted the least, possibly due to the higher level of training and inputs required for successful adoption. Ordered probit regression analysis shows that, five variables were statistically significant at $1 \%$ level for practicing IPM 
technology, they were; experience, training, MPC, mass media, and farmer field school. Two variables were statistically significant at $5 \%$ level for practicing IPM technology, they were; awareness of pesticides alternatives and field day. One variable age is statistically significant at $10 \%$ level for practicing IPM technology. Seven others variables namely gender, total family member, education, farm area, extension agent, credit and visit were statistically non significant. The sign of the coefficient in the coefficient columns shows the type of impact, positive or negative, by the particular variable.

\section{References}

[1] Crissman, C., P. Espinosa, C. E. H. Ducrot, D. C. Cole, and F. Carpio. "The Carchi Study Site: Physical, Health, and Potato Farming Systems in Carchi Province." Economic, Environmental, and Health Tradeoffs in Agriculture: Pesticides and the Sustainability of Andean Potato Production, C. Crissman, J. Antle and S. Capalbo, eds. Boston: Kluwer Academic Publishers, 1998.

[2] Feder G., R. E. Just, and D. Zilberman. 1985. "Adoption of Agricultural Innovations in Developing Countries: A Survey." Economic Development and Cultural Change 33(2): 255-298.

[3] Wooldridge, J. M. 2006. Introductory econometrics: A modern approach. Mason, OH: Thomson/South-Western.

[4] Mauceri, M. "Adoption of Integrated Pest Management Practice: A Case Study of Potato Farmers in Carachi Ecuador.” M. S., Virginia Tech, 2004.

[5] Feder, G. and D. L. Umali. 1993. "The Adoption of Agricultural Innovations A Review." Technological Forecasting and Social Change 43: 215-239.

[6] Wooldridge, J. M. 2002. Econometric analysis of cross section and panel data. Cambridge, Mass: MIT Press.

[7] Mullen, J. D., G. W. Norton, and D. W. Reaves. 1997. "Economic Analysis of Environmental Benefits of Integrated Pest Management." Journal of Agricultural and Applied Economics 29(2): 243-253.

[8] Rauniyar, G. P., and F. M. Goode. 1996. "Managing Green Revolution Technology: An Analysis of a Differential Practice Combination in Swaziland." Economic Development and Cultural Change 44(2): 413-437.

[9] Bonabana-Wabbi, Jackline. Assessing Factors Affecting Adoption of Agricultural Technologies: The Case of Integrated Pest Management (IPM) in Kumi District, Eastern Uganda.
MS thesis, Virginia Polytechnic Institute and State University, 2002.

[10] IPM CRSP. (2008c). IPM CRSP Countries at a Glance. Retrieved 09/08/08, from http://www.oired.vt.edu/ipmcrsp/IPM_2008/Countries.htm.

[11] De Souza-Filho, H. M., T. Young, and M. P. Burton. 1999. "Factors Influencing the Adoption of Sustainable Agricultural Technologies Evidence from the State of Espirito Santo, Brazil." Technological Forecasting and Social Change 60:97112.

[12] Adesina, A., and M. Zinnah. Technology characteristics, farmers. Perceptions and adoption decisions: A Tobit model application in Sierra Leone.. Agricultural Economics 9(1993):297-311.

[13] Feder G., and R. Slade. 1984. "The Acquisition of Information and the Adoption of New Technology." Amer. J. of Agri. Econ. 66(3):312-320.

[14] Chaves, B., and J. Riley. 2001 "Determination of factors influencing integrated pest management adoption in coffee berry borer in Colombian farms." Agriculture, Ecosystems \& Environment 87, (2):159-177.

[15] Adesina, A. A., D. Mbila, G. B. Nkamleu, and D. Endamana 2000. "Econometric analysis of the determinants of adoption of alley farming by farmers in the forest zone of southwest Cameroon." Agriculture, Ecosystems \& Environment 80(3): $255-265$.

[16] CBS 2011, National Population and Housing Census.

[17] Borooah, V. K. 2002. Logit and probit: Ordered and multinomial models. Thousand Oaks, CA: Sage Publications.

[18] Nhemachena, C. and R. Hassan. 2007. Micro level analysis of farmers' adaptation to climate change in Southern Africa. IFPRI Discussion Paper No. 00714. International Food Policy Research Institute, Washington D.C.

[19] Gbetibouo, G. A. 2009. Understanding farmers' perceptions and adaptations to climate change and variability, the case of the Limpopo Basin, South Africa. IFPRI Discussion Paper No. 00849. Environment and Production Technology Division, International Food Policy Research Institute.

[20] Feder G., R. Murgai, and J. B. Quizon. The Impact of Farmer Field Schools in Indonesia. World Bank Policy Research Working Paper 3022. April 2003.

[21] Negatu, W. and A. Parikh. The impact of perception and other factors on the adoption of agricultural technology in the Moret and Jiru Woreda (district) of Ethiopia.. Agricultural Economics 21(1999): 205-216. 